\title{
PERCEPÇÃO DE GÊNERO POR MEIO DE CARACTERÍSTICAS ACÚSTICAS DA FALA E VARIABILIDADE DO PITCH
}

\author{
Eduardo BARBUIO* \\ Suzana Ferreira PAULINO**
}

- RESUMO: A pesquisa objetivou analisar a percepção de gênero foneticamente, pela variabilidade do pitch, na fala de 14 homens, 7 que se autodeclararam gays e 7 autodeclarados heterossexuais. Os áudios foram submetidos a testes de percepção e julgados por ouvintes juízes leigos. Utilizaram-se os pressupostos teóricos da Sociolinguística Variacionista de Labov (2008 [1972]) e Eckert (1989, 1997, 2000, 2003, 2005, 2012; ECKERT; MCCONNELL-GINET, 2010), e testes de percepção da fala realizados por Gaudio (1994); Smyth, Jacobs e Rogers (2003); Levon (2007); Campbell-Kibler (2011); entre outros. Médias maiores de variabilidade do pitch dos informantes gays foram verificadas. Na maioria dos aspectos, as médias dos informantes homossexuais da pesquisa, aproximaram-se mais das médias dos informantes gays participantes das pesquisas em língua inglesa que das médias apresentadas por nossos informantes heterossexuais. Assim, devido às semelhanças encontradas nos resultados de algumas pesquisas, parece plausível afirmar haver alguns aspectos universais característicos e típicos de uma "fala gay".

- PALAVRAS-CHAVE: sociolinguística; variação linguística; percepção linguística; fonologia; fala gay.

\section{Introdução}

A presente investigação lança o olhar sobre um fenômeno da variação que a Sociolinguística adota ao trabalhar com dados de fala legítimos, produzidos por falantes gays. O objetivo foi pesquisar os mecanismos que regulam a variação, como ela interage com os outros elementos do sistema linguístico e da matriz social em que ocorre, e como essa variação pode levar às mudanças e fenômenos da língua. De acordo com Mollica (2008), cabe à Sociolinguística investigar o grau de estabilidade ou de mutabilidade da variação, diagnosticar as variáveis que têm efeito positivo ou negativo sobre a

Universidade Federal Rural de Pernambuco (UFRPE). Recife - PE - Brasil. eduardo.barbuio@ufrpe.br. ORCID: 0000-0002-2891-0095.

** Universidade Federal Rural de Pernambuco (UFRPE). Recife - PE - Brasil. suzana.paulino@ufrpe.br. ORCID: 0000-0002-9488-8455. 
emergência dos usos linguísticos alternativos e prever seu comportamento regular e sistemático. Um estudo sociolinguístico visa a descrever um determinado fenômeno do uso da língua, tendo como objetivo analisar variantes linguísticas, usadas por uma mesma comunidade de falantes, calculando a influência que cada fator, interno ou externo ao sistema linguístico, pode exercer na realização de determinadas variantes. Assim, a análise sociolinguística busca estabelecer as relações entre os processos de variação que se observam na língua.

Em grande medida, a língua denuncia quem são seus falantes, sua origem geográfica, a faixa etária, sua inserção cultural (por meio do nível de domínio da variedade padrão), as atitudes em relação a determinados grupos de falantes, o valor social que certas formas incorporam, e a importância desses valores para as questões relativas às identidades dos e entre falantes. É comum em nossa sociedade a ideia de que, a partir da audição da voz de falantes, inúmeras características possam ser percebidas, tais como: sexo, faixa etária, estado emocional, atitudes, identidade social etc. As características da fala de um determinado indivíduo podem, sutil ou abertamente, transmitir informações sobre sua associação em certos grupos sociais.

Diante disso, levantamos algumas questões, norteadoras da pesquisa:

1. Os juízes (ouvintes leigos) conseguem perceber a orientação sexual dos falantes (informantes homens homossexuais e homens heterossexuais) a partir da audição de suas vozes?

2. Esses juízes leigos percebem melhor a orientação sexual dos falantes que têm a mesma orientação sexual que a sua?

3. É possível identificar algumas peculiaridades acústicas na fala de homens homossexuais e heterossexuais que diferenciam as suas vozes?

No Brasil, ainda há poucos trabalhos relacionados às questões da linguagem que buscam dar conta de problemáticas envolvendo a sexualidade. A pesquisa teve como objetivo, avaliar a existência de características fonéticas de falas lidas por falantes do sexo masculino que podem ser usadas para identificá-los como de orientação sexual gay ou heterossexual a partir da variabilidade do pitch na fala lida de 14 homens recifenses, separados em dois grandes grupos. Para melhor compreender essas características fonéticas, o registro em áudio da voz desses homens foi submetido a testes de percepção e, posteriormente, julgado por ouvintes leigos. Objetivamos, com tal metodologia, atribuir valores de orientação sexual à fala de cada informante, e, a partir das percepções desses ouvintes leigos, tais características acústicas serão analisadas.

Nossa hipótese é que os 75 ouvintes (juízes leigos) deverão ser bem sucedidos em suas tentativas de perceber a orientação sexual dos informantes, ao ouvirem os trechos de fala gravados. Isso se fundamenta no fato de que estudos anteriores já provaram que é possível identificar a orientação sexual de falantes por meio de testes de percepção de voz (GAUDIO, 1994; LINVILLE, 1998; ROGERS; SMYTH, 2003; MUNSON; MCDONALD; DEBOE; WHITE, 2006; LEVON, 2007; TRACY; BAINTER SIERRA; SANTARIANO, 2015). Também nos embasamos na ideia de que provavelmente haverá melhor proficiência de julgamento, quando cada conjunto de juízes avaliar a 
fala do grupo de informantes que tenham a mesma orientação sexual que a sua. Para buscarmos essas respostas, nos apoiaremos nos pressupostos teóricos da Sociolinguística Variacionista de Labov (2008 [1972]) e Eckert (1989, 1997, 2000, 2003, 2005, 2012; ECKERT; MCCONNELL-GINET, 2010), e sobre testes de percepção da fala, inspirados por trabalhos desse tipo, realizados, dentre outros, por Gaudio (1994), Smyth, Jacobs e Rogers (2003), Levon (2007), Campbell-Kibler (2011), Lopes (2012) e Tracy, Bainter Sierra e Santariano (2015).

\section{A variação linguística e a fala na perspectiva da identidade de gênero}

A Sociolinguística focaliza o estudo da língua em uso entre os indivíduos de comunidades de fala, com atenção voltada a um tipo de investigação que correlaciona aspectos linguísticos e sociais. Essa ciência atua no universo que surge a partir da língua e da sociedade, voltando sua atenção para os empregos linguísticos concretos, principalmente os de caráter heterogêneo. Em trabalhos sociolinguísticos, desenvolvidos em pesquisas de língua inglesa, o termo sociophonetics, que seria 'sociofonética', é usado como um sinônimo para definir pesquisas com temática próxima aos trabalhos pioneiros desenvolvidos por Labov (FOULKES; DOCHERTY, 2006). Esses estudos sociofonéticos em língua inglesa concentram-se em aspectos fonéticos e fonológicos e em outras características sociais, como peculiaridades de fala e o ambiente social em que o falante interage, tendo interesse particular na compreensão das origens e no desenvolvimento de processos de variação e mudança linguística. Portanto, essas variações sociofonéticas referem-se a como as variações e os aspectos fonéticos e fonológicos podem se relacionar com fatores sociais. Entre os fatores, podemos mencionar os de gênero, faixa etária, etnia, origens geográficas, afiliações a determinados grupos, classe social e estilo de fala (FOULKES; DOCHERTY, 2006).

Variações sociofonéticas se referem às estruturas sonoras da língua em relação às variações encontradas em uma determinada sociedade, em que o indivíduo se relacione, ou em um dado grupo social em que esteja inserido, ou ao qual seja afiliado (MUNSON, 2007). Dessa forma, determinadas peculiaridades linguísticas podem se tornar marcas de diferenciação de grupos sociais, mesmo que não sejam necessariamente utilizadas por todos os membros do grupo. Em outras palavras, tais particularidades linguísticas podem até não ser necessariamente exclusivas de determinados grupos sociais, e apenas utilizadas pelos elementos desse conjunto (ROGERS; SMYTH, 2003).

As dinâmicas das línguas podem ser percebidas por meio de diversas manifestações heterogêneas em variadas comunidades de fala. Para Labov (2008 [1972]), o conceito de comunidade de fala não deve ser entendido apenas como um determinado grupo de pessoas que falam exatamente do mesmo jeito, mas sim, como falantes que compartilham traços linguísticos por meio dos quais é possível distinguir seu grupo de outros; e se comunicam relativamente mais entre seu grupo do que com outros e, principalmente, compartilham atitudes e normas com relação ao uso da linguagem. A ideia de que a 
orientação sexual de um indivíduo pode ser percebida a partir de sua fala é bastante popular em nossa sociedade. Diz-se até mesmo que aquele que tem uma boa percepção para reconhecer se determinada pessoa é gay, a partir de sua fala, possui um apurado 'gaydar'. O termo surgiu a partir da junção das palavras da língua inglesa gay e radar, formando assim, a palavra gaydar. Esse termo começou a ser utilizado por homossexuais americanos e hoje é usado por comunidades de gays ao redor do mundo.

O gaydar seria o conjunto de habilidades perceptivas que alguém usaria para descobrir se uma determinada pessoa, cuja condição sexual é desconhecida, seria ou não gay, a partir da observação de seus hábitos, comportamento, estilo e aparência. Incluem-se nesse conjunto de manifestações comportamentais, elementos como as roupas, os gestos, o corte de cabelo, o uso de acessórios e outras características, sendo considerada a voz como o traço mais evidente para a identificação da sexualidade (ZWICKY, 1997).

A fala transmite muitas informações que permitem que um ouvinte familiarizado a tais características, identifique o falante por meio de certas peculiaridades acústicas (MUNSON, 2007). Sinais da fala podem ainda carregar mensagens sobre grupos sociais dos quais os indivíduos participam, e, podem ainda oferecer sinais sobre a orientação sexual dos falantes. Segundo Lakoff (1987), se um homem faz uso de características que são geralmente atribuídas à fala de mulheres, este falante pode ser percebido como um homem gay. De acordo com o autor, um exemplo desse fenômeno estaria no fato de que as mulheres possuem maior variabilidade de contorno entonacional, sendo tal característica um dos atributos da fala feminina na maioria das línguas.

No entanto, esse pensamento de Lakoff não é consenso, sendo desacreditado por muitos pesquisadores. Questões relacionadas a pesquisas de percepção da fala e orientação sexual podem apresentar ideias equivocadas de que pessoas que se declaram como fazendo parte de uma determinada orientação sexual, certamente falam do mesmo modo, apresentando todos, as mesmas características de produção da voz. Segundo Kulick (2000), é preciso provar que as características acústicas da fala de uma pessoa, que se declara de uma determinada orientação sexual, estejam presentes nas vozes de todas as outras pessoas que se declaram da mesma orientação. A linguagem gay, em particular, tem sido referida de modo bastante vago. Há pessoas que equiparam a fala gay às características da fala feminina. Na cultura popular, em programas de comédia, charges, memes da internet, geralmente, retrata-se a fala de gays com voz de características femininas muito marcadas e evidentes. Nesses meios, a fala gay é introduzida de forma caricata, apresentando características como alongamentos, entonações oscilantes e fala reproduzida com alta frequência fundamental, entre outras características que fazem referência à voz de mulheres.

Contudo, a ideia do que caracteriza a fala gay tem sido debatida em diferentes pesquisas nos últimos anos. Alguns estudiosos têm considerado características linguísticas específicas que sugerem uma forma gay de falar; que em língua inglesa tem sido referido como "gay accent", o que poderíamos compreender como "sotaque gay”. Em trabalhos realizados por pesquisadores como Gaudio (1994), Linville (1998) e 
Smyth, Jacobs e Rogers (2003), a suposta fala gay, referida como gay accent, apresenta peculiaridades linguísticas que podem ser percebidas no léxico, discurso e fonética.

Atualmente, há a tendência de uma nova perspectiva em relação aos processos de construção de identidade que compõem o indivíduo e as suas implicações para a construção dos grupos sociais e da sociedade. Assim, investigar a percepção e as características linguísticas, presentes na fala de grupos específicos de homens gays e heterossexuais, representa o interesse de discutir questões fundamentais atuais da Sociolinguística e de debater o significado social da variação. O interesse de pesquisadores sobre como se dá a percepção em relação à orientação sexual guiou a realização desta pesquisa. Por sua vez, a escassez de trabalhos acadêmicos, relacionados às investigações acerca da fala de homens gays e heterossexuais nos estudos da Sociolinguística Variacionista, além da ausência de pesquisas com ênfase nos aspectos fonológicos e perceptivos em língua portuguesa, justificam a relevância deste trabalho.

Segundo Lopes (2012), os estudos sociolinguísticos, e em especial os estudos da sociofonética, consideram muito relevantes os fatores sociais na percepção da fala. A produção de certas variáveis linguísticas evidencia as variáveis sociais dos falantes. Por outro lado, os atributos sociais relacionados a um falante, desempenham um papel importante no julgamento dos ouvintes durante uma tarefa de percepção. A língua falada carrega consigo fortes características identificadoras de membros pertencentes a um determinado grupo social, e este é um comportamento comum a todos os indivíduos.

A variabilidade é uma das características inerentes à fala humana; não há duas vozes que sejam exatamente idênticas. A variação linguística é parte integrante do universo das relações sociais, por meio das quais os falantes constroem um mundo social e nele se inserem, se relacionam e interagem. (CAMPBELL-KIBLER, 2009). Os traços linguísticos diferenciam as comunidades de fala e é nesse contexto que se desenvolvem as peculiaridades das vozes dos falantes que conectam os padrões linguísticos com fatores sociais de determinados grupos (ECKERT, 2003; CAMPBELL-KIBLER, 2007). Todos os indivíduos pertencem a, pelo menos, uma comunidade de fala, e é o uso das variações e normas linguísticas que afiliam os indivíduos em uma comunidade (RYAN; GILES; SEBASTIAN, 1982). Por ser produto de um comportamento social e cultural, a língua sofre variações, de acordo com o ambiente onde se encontra inserida. Por causa da diversidade e da heterogeneidade da língua, Tarallo (2007) expõe que a teoria sociolinguística tem por objetivo maior analisar e sistematizar as diferentes variantes linguísticas, utilizadas por uma mesma comunidade linguística. É por essa razão que, para os estudos sociolinguísticos, o objeto de estudo é a comunidade de fala e não só o indivíduo.

Entre os estudos da Sociolinguística, da mesma forma que nas demais ciências sociais, nenhuma variável social está totalmente separada de outra; a variável sexo/ gênero é, na verdade, um rótulo amplo que recobre diferentes nuances sociais e estilísticas (ECKERT, 1997). Diante disso, a variável sexo tem sido muitas vezes 
denominada por "sexo/gênero", uma vez que engloba muito mais do que exclusivamente a dimensão biológica. É comum a apresentação "sexo/gênero" ser utilizada para considerar os papeis sociais desempenhados por homens e mulheres ou, em outras palavras, a forma por meio da qual as construções identitárias de gênero, no caso, feminina ou masculina, perpassam pelas questões linguísticas. Essa representação binária traz consigo um desafio para os estudos da Sociolinguística. O tradicional recorte sociolinguístico tem apresentado uma sociedade bipolarizada, no que diz respeito ao gênero, em que só existem homens e mulheres. Esse conceito mostra-se polarizado, não apenas em uma dimensão mais tradicional, que inclui a perspectiva biológica do ser, mas também na que envolve sua perspectiva social. É dessa maneira que a sociedade tem sido representada nas amostras sociolinguísticas.

De acordo com Eckert e McConnell-Ginet (2010, p. 10), para que se possa entender gênero como construção social, é preciso considerar que "gênero não é algo com o qual nascemos, nem é também algo que temos, mas sim, algo que fazemos ou como atuamos". Podemos, portanto, falar em uma performance de gênero, e não nos limitarmos a compreender o gênero pelo viés de uma perspectiva puramente biológica. Nos dias de hoje, há outras preocupações e inquietações na sociedade no que diz respeito às discussões em torno do gênero. E é certa a relevância da codificação da variável sexo em busca de uma melhor compreensão das representações sociais do gênero. Isso porque, se as sociedades mudam, é preciso que o foco dos estudos, envolvendo as relações entre língua e sociedade, também evolua, e, assim, modifique e adeque suas perspectivas e modelos teóricos e metodológicos.

Através da fala é possível ter impressões a respeito de características sociais relevantes sobre o interlocutor. Essas impressões podem variar, incluindo suposições sobre a idade, o nível de escolaridade ou o sexo/gênero do interlocutor. Desse modo, apenas por meio da audição da voz do interlocutor, pode-se associar uma identidade a tais características. Seria possível ainda, tecer considerações sobre o estado emocional ou psicológico do falante. Ou seja, detectar a condição de humor do interlocutor; como estando este em um momento de nervosismo, ansiedade, excitação ou infelicidade.

Nos últimos anos, as pesquisas variacionistas têm dedicado mais atenção ao conceito de significado social, ou seja, à ideia de que falantes e ouvintes fazem uso de certas características linguísticas para moldar situações e relações sociais das quais participam. O link entre posicionamento social e escolhas linguísticas foi estabelecido desde os primeiros anos das pesquisas sociolinguísticas (LABOV, 1963), e o entendimento que se tem a respeito de significado social e tem se expandido acompanhando a evolução da sociedade.

Inerente a essa ideia de construção das relações sociais, há o pensamento de que, para todos os indivíduos inseridos em uma sociedade, seja na condição de falante ou ouvinte, a variação linguística está conectada à percepção de vários aspectos das estruturas sociais. Não só o comportamento linguístico e outras estruturas sociais se relacionam, mas que isso acontece porque falantes e ouvintes estão mentalmente conectados a tais percepções, de maneira consciente ou não. Portanto, a partir dessas 
percepções sociais há uma avaliação e um posicionamento segundo os quais acontecem os julgamentos de atitudes dos indivíduos (CAMPBELL-KIBLER, 2007). A maior parte da evidência da existência de um vínculo entre significado social e variação se dá por meio dos estudos de produção linguística, que documentaram as correlações entre variações e categorias sociais (ECKERT, 2000; LABOV, 1966).

Uma das pesquisas precursoras foi desenvolvida por Labov (1966), relacionada ao estudo do inglês falado na cidade de Nova Iorque. Por pressupor que a variação linguística é estruturada pelo estilo e pela classe social dos falantes e que a escala de formalidade (estilo) está conectada à condição social do indivíduo, o pesquisador realizou um experimento em que cinco mulheres nova-iorquinas tiveram suas vozes gravadas ao lerem um pequeno texto. Como etapa subsequente do experimento, foram selecionados entre as gravações, trechos da leitura que continham as diferentes variações linguísticas pretendidas. Esses trechos com a gravação das vozes foram expostos a 112 ouvintes, nova-iorquinos, que desempenharam o papel de juízes. Os ouvintes eram de variadas idades, etnias, classes socioeconômicas e sexo.

Resultados indicaram que as variantes favorecidas pelas classes sociais mais privilegiadas receberam julgamentos mais altos, na escala de adequação ocupacional, do que as variantes favorecidas pelos falantes de status socioeconômico mais baixo. Essa correlação se reproduziu em todas as classes sociais e grupos étnicos observados. A partir dos resultados obtidos, pode-se concluir que a estratificação social da língua inglesa falada na cidade de Nova Iorque é bastante arraigada, sendo bem reconhecida pelos membros da comunidade linguística.

Para Gibson (1991 [1977]), a percepção pode ser compreendida como uma extração de informações sobre as coisas do mundo. Portanto, perceber significa extrair dados e informações relevantes sobre os eventos, o que faz com que o ouvinte seja capaz de fazer um julgamento sobre o que é percebido. Também para Fiske e Neuberg (1990), os indivíduos, ao formarem impressões sobre os outros, usam um padrão cognitivo, que envolve uma categoria social a partir da qual as características individuais são percebidas. Categorias sociais como sexo/gênero e faixa etária são percebidas rapidamente durante a escuta de um trecho de fala.

Segundo Edwards (1999), a percepção pode ser considerada um filtro por meio do qual os dados sensoriais são, em um primeiro momento, analisados, e então registrados. Para tanto, é necessário considerar o contexto de produção em que o indivíduo se insere e o conjunto ímpar das experiências e vivências que esse indivíduo possui. Desse modo, o significado social que os membros do grupo apresentam em comum, desde a ideia de estereótipos até o compartilhamento da própria cultura e fala, tem importante papel. Ainda dentro dessa perspectiva, Campbell-Kibler (2007), contribui com a hipótese de que indivíduos de uma determinada comunidade de fala atribuem e se utilizam de significados sociais para perceber e fazer uso de sua língua. 


\section{A Fonética Acústica}

A Fonética Acústica estuda os sons da fala a partir de suas propriedades físicas, os descrevendo e quantificando, e mostrando como a qualidade desses sons está relacionada com a forma de produzi-los. Esse estudo é processado sobre a cadeia da fala, ou seja, por meio da análise das ondas sonoras. A análise acústica é uma análise objetiva que faz uso de programas computadorizados e que, no Brasil, alcançou maior utilização e desenvolvimento nas últimas décadas, quando os estudos na área se tornaram mais abrangentes a partir do desenvolvimento de novas tecnologias. Cada indivíduo, ao produzir os movimentos necessários para a realização da fala, apresenta características exclusivas, que tornam sua fala uma produção acústica única.

Ao se realizar a análise acústica da fala, é possível identificar traços característicos da produção exclusiva de cada falante. Por meio de elementos gráficos e resultados numéricos e estatísticos, pode-se realizar variadas análises de produções acústicas, mesmo que aconteçam em uma fração de tempo bastante pequena, pela dinâmica das informações ocorridas durante a fala. Um som não é apenas uma produção por parte do falante, é também uma entidade física, que é percebida por ouvintes.

Por outro lado, os estudos da fonética acústica focam nas propriedades físicas dos sons, tais como: duração, frequência fundamental, intensidade etc, que, entre outros, são fatores determinantes para que um som possa ser ouvido e percebido como diferente de outros (CRYSTAL, 1988). Apesar de haver uma Fonética Articulatória e uma Acústica, existe uma relação estreita entre as propriedades articulatórias e acústicas dos sons da fala. O fato é que as propriedades acústicas derivam das propriedades articulatórias, ou seja, a movimentação dos articuladores (mandíbula, língua e lábios) gera modificações nas frequências formânticas, estando estas, portanto, condicionadas ao posicionamento daqueles no momento da produção de um dado som. Pode-se dizer que o sinal acústico representado no espectrograma é o resultado da total configuração do aparato vocal durante a produção de um som.

\section{Frequência fundamental (pitch)}

Uma das características físicas mais básicas de um som é a sua frequência fundamental, que se caracteriza por ser o número de vezes que as partículas de ar vibram num determinado intervalo de tempo; isto é, é a frequência de repetição de uma onda sonora complexa (LADEFOGED, 1967). Sua medida é feita em ciclos por segundo, que correspondem à velocidade na qual uma forma de onda se repete por unidade de tempo (COUPER-KUHLEN, 1986).

Segundo Braid (2003), a frequência fundamental da voz, normalmente também referida pela sigla F0, é o menor componente periódico resultante da vibração das pregas vocais e a primeira frequência produzida na glote. A frequência fundamental das pregas vocais é determinada por uma complexa interação entre comprimento, massa e tensão 
(COLTON; CASPER, 1996). Lehiste (1970) concorda com os autores e considera que a pressão subglótica e a lubrificação das pregas vocais também têm papel importante na determinação da frequência fundamental, além da massa, comprimento e tensão das pregas vocais.

No nível perceptivo, esta frequência representa, para os ouvintes, o correlato acústico responsável pela percepção da melodia, ou seja, é percebida como a altura melódica da voz, ou tom (KENT; READ, 1992). A frequência fundamental (F0) é considerada o mais importante dos parâmetros para que se tenha a percepção de altura (sons agudos ou graves) e também de intensidade (sons fortes ou fracos) de vozes. Quanto maior ou menor uma frequência, respectivamente maiores e menores serão a altura e a intensidade dos sons. A respeito da percepção da frequência fundamental (F0), Braid (2003, p. 51) considera que "Em análise de fala, as taxas de repetição dos padrões periódicos numa forma de onda são denominadas frequência fundamental, entretanto, perceptualmente, esta impressão auditiva é chamada de pitch. $\mathrm{O}$ pitch corresponde à sensação de som grave ou agudo, e suas escalas".

Portanto, em nosso trabalho, nos referimos à altura dos sons (agudos ou graves) como pitch. O hertz é a unidade de medida utilizada para mensurar os sons, e é representada pelo símbolo $\mathrm{Hz}$. Importa ressaltar que, quando nos referirmos aos valores de um pitch em $\mathrm{Hz}$, esses aparecerão por meio do símbolo F0. As pessoas com vozes dentro de uma faixa mais aguda são consideradas como tendo um pitch alto, por conseguinte, as de vozes mais graves, pitch baixo. Portanto, os sons de menor pitch, ou de menores valores de F0, são mais graves, a exemplo das vozes masculinas, que geralmente apresentam um pitch médio de cerca de $120 \mathrm{~Hz}$. Já as vozes femininas apresentam um pitch mais alto, com valores médios de F0 de $230 \mathrm{~Hz}$ (KENT; READ, 2015). Ou seja, o F0 da voz feminina é geralmente o dobro da masculina. Essa diferença é resultante da maior quantidade de massa vibrante ser maior em homens, devido ao maior volume de suas pregas vocais, o que faz com que elas vibrem em uma velocidade mais lenta, gerando menos ciclos glóticos por segundo.

Independente da característica pessoal de voz (grave ou aguda), as pessoas alteram o pitch durante sua fala, pois ele é responsável pela entonação. Diversos autores, dentre eles Cruttenden (1986), Pierrehumbert (1987) e Moraes (1993) consideram o pitch como a característica prosódica mais importante da entonação. Todo falante, ao proferir sua voz, produz naturalmente variação do pitch. Isso acontece pelos diversos tons que são usados para se expressar. Ao se realizar a análise do traçado gráfico, o qual geralmente é referido como curvas de contorno de pitch, são encontrados os valores instantâneos da frequência fundamental em função do tempo (BRAID, 2003). Consideramos que possa haver certa relação entre os resultados dos testes de percepção, respondidos pelos juízes, e as características do pitch das vozes de nossos informantes. Neste estudo, avaliamos a média geral do pitch, por ser um parâmetro utilizado nas pesquisas realizadas em língua inglesa com informantes gays e heterossexuais. Também verificamos a média de variabilidade, por meio da mensuração dos valores de menor e maior valor do pitch, das vozes dos informantes. 
Por meio do parâmetro da variabilidade, buscamos verificar se nossos resultados assemelham-se aos encontrados por Munson, Jefferson e McDonald (2006), que, em sua pesquisa, verificou médias extremas de valores de F0 na fala dos informantes gays, com picos bem mais altos e valores mínimos bastante inferiores às médias apresentadas pelos informantes heterossexuais. Trata-se, pois, das características chamadas por Kulick (2000) de "roller coaster intonation" e que seriam peculiaridades de variabilidade de pitch, encontradas em falas de mulheres com vozes percebidas como mais agudas. Em todas as análises de produção, fizemos uso do software de análise acústica e de síntese de voz chamado PRAAT (BOERSMA; WEENINK, 2021). Para obter os valores de média de pitch e os valores mínimos e máximos de trechos da fala de cada informante, usamos o recurso de análise de pitch disponível no menu "PITCH" do software PRAAT, estando o 'get pitch' marcado em azul, como podemos ver na Figura 1:

Figura 1 - Procedimentos de análise da média e de valores máximos e mínimos de pitch.

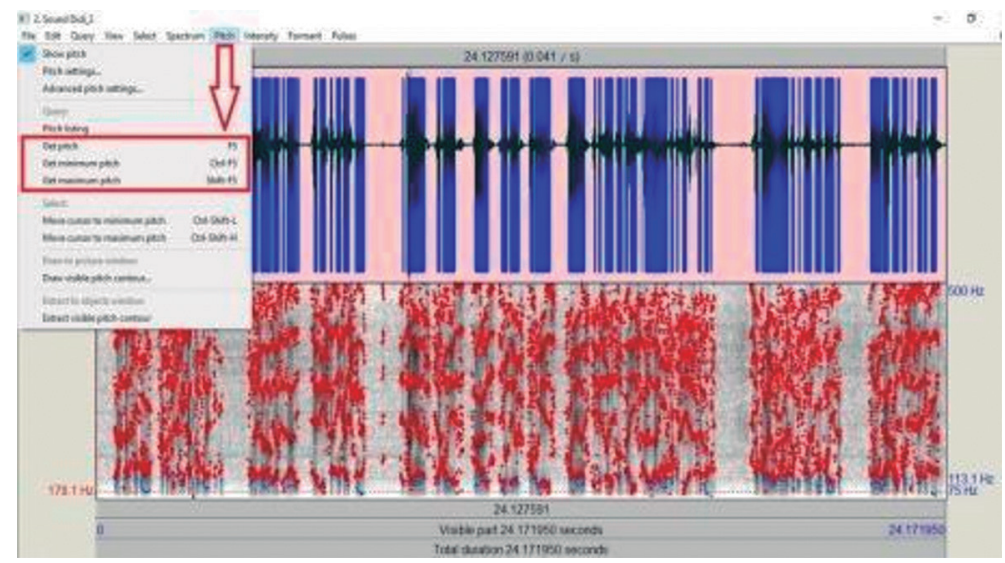

Fonte: Elaboração própria.

Os valores de média geral de pitch, valores mínimos, máximos e de variabilidade, serão obtidos a partir da verificação das vozes de cada um dos 14 informantes. Em seguida, faremos as médias apresentadas pelos 7 informantes que compõem o grupo formado por homens gays e dos outros 7 que formam o grupo dos homens heterossexuais. A partir daí, buscaremos compreender se há diferenças significativas de pitch, entre esses grupos. Outro de nossos objetivos será relacionar tais medidas com os resultados dos testes de percepção de orientação sexual.

"Entonação de montanha russa". 


\section{Metodologia}

Nossa pesquisa se caracteriza como um estudo de cunho descritivo, uma vez que seu objetivo central é o de identificar a possível relação entre certas características da produção acústica, encontradas na fala dos informantes e a percepção, que os ouvintes (juízes leigos) tiveram, sobre a orientação sexual desses informantes (homossexuais ou heterossexuais). Esses dados foram obtidos, a partir da audição, realizada pelos juízes leigos, de trechos lidos por nossos informantes, e gravados em áudio.

Num primeiro momento, participaram de nossa coleta de dados 14 informantes, que aceitaram participar dos trabalhos e autorizaram, voluntariamente, ter suas vozes gravadas em áudio. Essas gravações envolveram a leitura de um trecho com a duração de aproximadamente 35 segundos (cf. Anexo 1). Entre todos os informantes, 7 se declararam exclusivamente de orientação heterossexual e os outros 7 de orientação exclusivamente homossexual. Foi revelado aos 14 informantes que a pesquisa teria por objetivo a percepção da orientação sexual de cada um, por meio da audição de suas falas, após as gravações terem sido realizadas. Os 14 informantes são moradores de Recife - PE; todos nascidos na cidade, na qual passaram a maior parte da vida.

Em um segundo momento da pesquisa, participaram 75 juízes leigos que consentiram voluntariamente em ouvir os trechos das vozes gravadas pelos 14 informantes e atribuir valores a essas gravações, segundo suas percepções com relação à orientação sexual dos informantes. Os 75 juízes foram divididos em três grupos. O primeiro composto de 25 homens autodeclarados exclusivamente heterossexuais, o segundo por outros 25 homens autodeclarados exclusivamente gays, e o último formado por 25 mulheres, sem distinção de suas orientações sexuais.

A coleta das vozes dos 14 informantes foi realizada em uma sala, ambiente com ruído inferior a $50 \mathrm{~dB}$, sendo as vozes gravadas por meio de um microfone de mesa pedestal, modelo AC00040ML, com tecnologia antirruído, sensibilidade $38 \mathrm{dBV} / \mathrm{Pa}$, faixa de frequências de $50-16 \mathrm{kHz}(+/-3 \mathrm{db})$ e taxa de amostragem de até $48 \mathrm{kHz}$, conectado via cabo USB, a um notebook DELL Inspiron 14 Modelo 5000, com placa de som integrada. A gravação foi feita por meio do software PRAAT 4.1.44 (BOERSMA; WEENNINK, 2021), numa taxa de amostragem de $44.100 \mathrm{KHz}$. Foi pedido aos informantes que lessem um mesmo trecho de texto, em velocidade natural, como se estivessem lendo para um grupo de amigos próximos que estivessem presentes na sala. As partes da gravação selecionadas para o corpus da pesquisa foram do protocolo de Laver (VPAS) traduzido/adaptado por Camargo e Madureira (2008) ao português que, a partir do trabalho de Laver et al. (1981), criaram um protocolo de qualidade de voz de referência na análise fonética e fonoaudiológica do Brasil.

Para as análises estatísticas do teste de percepção, consideramos como variável dependente, o grau de atribuição sobre a orientação sexual do indivíduo que produziu os estímulos fornecidos aos juízes. Os valores dessa variável formaram uma escala gradativa de 1 a 5, sendo " 1 " o valor atribuído se o informante soasse mais heterossexual aos juízes, e "5", se o informante soasse mais gay, estando os outros números na 
interseção sobre esses dois extremos ${ }^{2}$. Dessa forma, temos uma variável contínua que pode apresentar valores entre 1 e 5 . Como estabelecemos as hipóteses alternativas de que (i) os juízes gays seriam mais proficientes na identificação dos informantes gays; (ii) os juízes heterossexuais seriam mais proficientes em reconhecer os informantes heterossexuais; (iii) as mulheres seriam proficientes na percepção dos dois grupos, temos como principal variável independente a orientação sexual/sexo (orientação sexual, no grupo dos homens vs mulheres) dos juízes.

Outrossim, para as análises estatísticas, verificamos, inicialmente, as respostas para todos os informantes gays e, depois, para todos os informantes heterossexuais, com o intuito de avaliar a proficiência de cada grupo como estabelecido nas hipóteses. O quadro expõe cada variável e seus níveis para as duas rodadas:

Quadro 1 - Variáveis Dependentes e Independentes do Teste de Percepção de Orientação Sexual

\begin{tabular}{|c|c|c|}
\hline Tipo & Descrição & Níveis \\
\hline Variável Dependente & $\begin{array}{c}\text { Grau de atribuição sobre } \\
\text { condição sexual do indivíduo } \\
\text { que produziu o estímulo }\end{array}$ & $1 ; 2 ; 3 ; 4 ; 5$. \\
\hline Variáveis Independentes & Orientação sexual/sexo & $\begin{array}{c}\text { Homem gay; Homem } \\
\text { heterossexual; Mulher. }\end{array}$ \\
\hline
\end{tabular}

Fonte: Elaboração própria.

O software utilizado em nossa análise estatística dos testes de percepção foi o $\mathrm{R}$, sendo este gratuito e o mais utilizado pela comunidade estatística. Gráficos com valores das médias dos testes de percepção e bloxpots, com os valores de percepção de sexualidade atribuídos aos informantes pelos juízes, também foram utilizados, para uma melhor apresentação e discussão dos dados levantados. Com relação à produção oral, analisamos pontos próximos aos que foram apontadas na literatura em língua inglesa (LEVON, 2007; PODESVA, 2007; MUNSON, 2007; CAMPBELL-KIBLER, 2011; TRACY; BAINTER SIERRA; SANTARIANO, 2015), como sendo as principais marcas distintivas da fala de homens gays e heterossexuais. Segundo a literatura pesquisada, um dos principais pontos, em que características da fala de homens gays se distanciou da fala de homens heterossexuais foi no pitch. No caso do pitch, os principais aspectos observados foram a média e a variabilidade. Isso se deu por meio da observação dos picos máximos e dos valores mínimos, ou seja, da variabilidade. A variabilidade corresponde à diferença entre a frequência máxima e a mínima encontradas em um determinado trecho, específico, de fala.

(1) Se o juiz tivesse certeza que se tratava de um informante heterossexual.

(2) Se o informante parecesse heterossexual ao juiz.

(3) Se o juiz não pudesse identificar com clareza a orientação sexual do informante.

(4) Se o informante parecesse heterossexual ao juiz.

(5) Se o juiz tivesse certeza que se tratava de um informante gay. 


\section{Análises dos dados e resultados}

\section{Análises do pitch}

Segundo Kent e Read (1992), para os ouvintes, o pitch é o correlato acústico responsável pela percepção da melodia, ou seja, é percebida como a altura melódica da voz, também referida por tom. Das pesquisas realizadas com falantes de língua inglesa, que objetivaram o estudo da percepção e de características de produção da fala de homens identificados como heterossexuais e homossexuais, a questão do pitch foi a mais frequentemente abordada. No que tange aos aspectos do pitch, abordados nesses estudos, quase todos os pesquisadores analisaram a média do valor de pitch e sua variabilidade, por meio da mediação de seus picos mais elevados e valores mais baixos de produção.

Embora algumas dessas pesquisas não tenham encontrado diferenças significativas com relação à média de pitch dos informantes (GAUDIO, 1994; LINVILLE, 1998; SMYTH; JACOBS; ROGERS, 2003; MUNSON; JEFFERSON; MCDONALD, 2006; MUNSON, 2007), considera-se esse um procedimento a ser levado em conta nesta pesquisa. Assim, optamos por ser o procedimento utilizado entre os parâmetros de análise sobre aspectos, envolvendo a fala de homens, e os que buscam dar conta da questão da orientação sexual. Além disso, ainda merece destaque o fato de não termos conhecimento de análises, anteriormente realizadas, que tenham incluído o pitch entre os propósitos das investigações, com falantes de língua portuguesa.

Desse modo, por meio do software PRAAT (BOERSMA; WEENINK, 2021), verificamos os valores de médias de pitch dos informantes do grupo formado por homens gays e de outro composto por homens heterossexuais. Por meio do gráfico 1, temos os valores conferidos por cada um dos dois grupos:

Gráfico 1 - valores de médias de pitch do grupo de homens gays e do grupo de homens heterossexuais em $(\mathrm{Hz})$

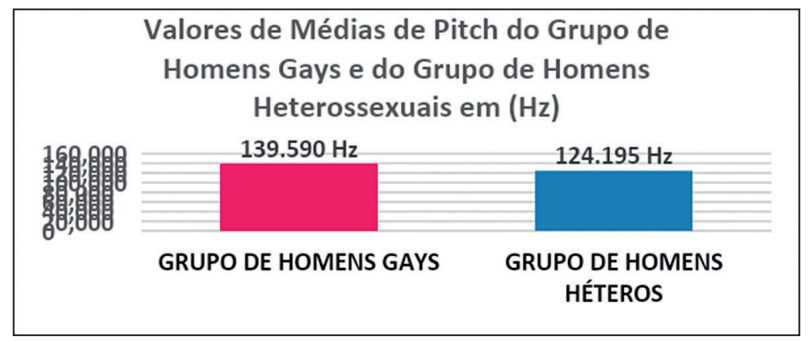

Fonte: Elaboração própria.

Segundo Kent e Read (1992), enquanto a média de pitch da voz de um falante homem geralmente varia em torno de 100 a $120 \mathrm{~Hz}$, a de mulheres se apresenta em torno de 200 a $220 \mathrm{~Hz}$. Com valores de 139,590 para o grupo de homens gays e de 
124.195 para o grupo de homens heterossexuais, pode-se afirmar que os valores de média de pitch de ambos são mais próximos aos que os autores consideram por uma média masculina. Portanto, mesmo o grupo dos gays, que apresentou uma média maior, ainda se revela distante da média feminina. A média do pitch do grupo de gays foi cerca de $11 \%$ maior que a média do grupo de heterossexuais. Essa diferença não se distancia muito das médias encontradas em outros estudos, em que médias de pitch de grupos de homens gays e heterossexuais foram comparadas. Gaudio (1994) observou uma diferença de $10 \%$ a mais, na média dos informantes gays. Na pesquisa de Munson, Jefferson e McDonald (2006), também os gays apresentaram uma média de pitch 7\% maior do que os heterossexuais. Os dois pesquisadores consideraram que essas médias não representam uma diferença relevante, e que teriam pouca influência no processo de percepção da orientação sexual dos informantes de suas pesquisas.

Pelos valores observados em nossa análise e, pelo fato da média do grupo gay apresentar uma diferença de cerca de $11 \%$ maior que a média dos heterossexuais, também não acreditamos que a média do pitch de nossos informantes seja um elemento que diferencie significativamente as peculiaridades da fala gay e da fala heterossexual, e, com isso, provavelmente não exercem grande influência no processo de percepção da orientação sexual dos informantes.

\section{Análises dos valores mínimos, máximos e de variabilidade do pitch}

A seguir, as médias dos valores mais elevados; as médias dos valores mais baixos registrados e as médias da variabilidade, que representa o valor mais baixo, subtraído do valor mais alto, apresentados pelos dois grupos de informantes:

Gráfico 2 - Médias dos maiores e menores valores e variabilidade do pitch dos informantes gays (rosa) e heterossexuais (azul) em (Hz).

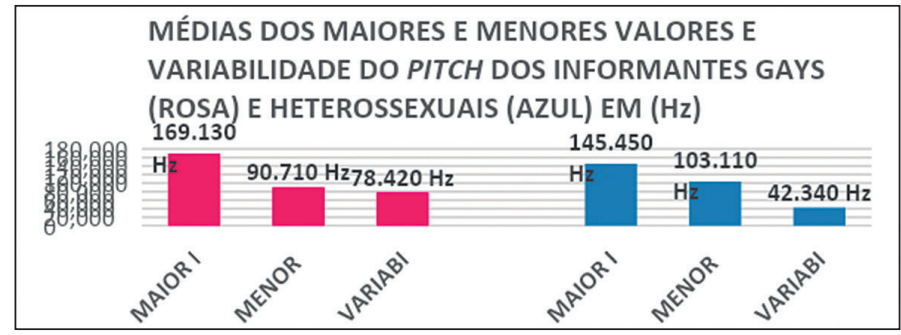

Fonte: Elaboração própria.

Ao observarmos os valores apresentados no gráfico 2, pode-se notar que as médias dos grupos de informantes gays e heterossexuais apresentaram valores diferentes nos três parâmetros observados. A média de valor de pitch mais elevado do grupo dos gays foi de $169.130 \mathrm{~Hz}$, contra $145.450 \mathrm{~Hz}$ dos heterossexuais. Trata-se, pois, de uma 
diferença de cerca de 14\% maior para os gays, o que nos permite concluir que as vozes dos informantes gays, participantes de nossa pesquisa, apresentaram picos um pouco mais agudos do que as vozes dos heterossexuais. Por outro lado, o valor médio de menor pitch apresentado pelo grupo gay foi mais baixo que o do grupo heterossexual (média de $103.110 \mathrm{~Hz}$ para os heterossexuais contra $90.710 \mathrm{~Hz}$ para os gays). Tais valores mostraram-se cerca de $12 \%$ menores, o que demonstra que, em alguns momentos das gravações utilizadas em nosso teste de percepção, os gays apresentaram vozes sutilmente mais graves que as dos heterossexuais.

A média de variabilidade, apresentada pelo grupo gay, foi cerca de $46 \%$ maior que a do grupo heterossexual, com médias de 78,420 Hz contra 42,340 Hz. Portanto, os valores de pitch mais altos e mais baixos, observados nas vozes dos informantes gays, apresentaram uma média de variabilidade consideravelmente maior do que a dos heterossexuais. Kulick (2000) denomina as vozes com variabilidade de pitch e presença de médias baixas e picos elevados de "roller coaster intonation", características mais observadas nas peculiaridades de vozes femininas. Embora os valores de média de pitch encontrados nas vozes dos falantes gays sejam menores que os valores médios de pitch atribuídos às vozes femininas, podemos considerar que a entonação de montanha russa seja uma característica peculiar da fala do grupo de informantes gays da pesquisa. Suas falas, porém, não se apresentam tão agudas quanto as vozes femininas. Entonação de montanha russa, em vozes não tão agudas quanto a de mulheres, também foram características de produção encontradas na fala de informantes do grupo de homossexuais em Smyth, Jacobs e Rogers (2003).

O trabalho de Munson, Jefferson e McDonald (2006) também concluiu que alguns informantes gays apresentaram variabilidades extremas de pitch; depressões com valores mais baixos e picos mais altos que a média dos informantes heterossexuais. No entanto, os pesquisadores consideraram que o número de participantes envolvidos em sua pesquisa era muito pequeno, e que essa característica foi observada somente na fala de 3 informantes. Ainda assim, em um estudo subsequente, realizado pouco tempo depois, com um número maior de informantes, os resultados encontrados em Munson (2007) não confirmaram essa suposta peculiaridade da "fala gay".

Em nossa pesquisa, consideramos que a chamada entonação de montanha russa (encontrada na fala dos informantes gays) - com uma taxa de variabilidade quase $50 \%$ maior do que entre os falantes heterossexuais - representa uma característica peculiar da fala do grupo de informantes gays participantes de nossa pesquisa, uma vez que todos os indivíduos homossexuais apresentaram essa mesma característica. Consideramos também que tal característica da fala dos gays tenha sido relevante para as atribuições de valor dos juízes, ao realizarem o teste de percepção de sexualidade. E, por confirmar os resultados encontrados em pesquisas realizadas com outros informantes também gays, falantes de língua inglesa (SMYTH; JACOBS; ROGERS, 2003; MUNSON; MCDONALD; DEBOE; WHITE, 2006), é possível que a chamada entonação de

"Entonação de montanha russa". 
montanha russa seja uma característica mais universal, típicas das comunidades de falas gays.

\section{Considerações finais}

Descobertas a respeito das peculiaridades da linguagem utilizada por pessoas de diferentes orientações sexuais têm sido realizadas por pesquisas linguísticas nos últimos anos (LEVON, 2007; PODESVA, 2007; MUNSON, 2007; CAMPBELL-KIBLER, 2011; TRACY; BAINTER SIERRA; SANTARIANO, 2015).

Este estudo teve como objetivo verificar se informantes, de diferentes orientações sexuais, apresentariam peculiaridades acústicas específicas em suas falas. Em se confirmando tal hipótese, o passo seguinte foi tentar compreender se essas peculiaridades acústicas poderiam ser atribuídas às características de fala particulares dos dois grupos, escolhidos para nosso estudo.

Diante disso, levantamos o seguinte questionamento: É possível identificar algumas peculiaridades acústicas na fala de homens heterossexuais e gays que diferenciem as suas vozes? Em nossos resultados, encontramos algumas particularidades típicas dos grupos de cada orientação sexual. Com relação ao pitch, a média de variabilidade apresentada pelo grupo gay foi cerca de $46 \%$ maior do que a do grupo heterossexual, com médias de $78,420 \mathrm{~Hz}$ contra $42,340 \mathrm{~Hz}$. Com isso, os valores de pitch mais altos e mais baixos, observados nas vozes dos informantes gays, apresentaram uma média de variabilidade consideravelmente maior do que a dos heterossexuais.

Foi observado que é possível que a chamada entonação de montanha russa seja uma característica mais universal, típicas das comunidades de falas gays, considerando que a afirmação de uma característica universal talvez precise de mais experimentos na área. Porém, o fato de confirmar estudos anteriores é um indício/evidência de importância para os estudos na perspectiva da pesquisa.

A variação linguística é inerente à linguagem humana e decorre de variados fatores intervenientes na forma linguística escolhida. A produção de certas variáveis evidencia as variáveis sociais do falante. A língua falada carrega consigo fortes características identificadoras de membros de um grupo social ou de uma comunidade de fala. Os resultados sinalizam para a possibilidade de que pesquisas futuras venham a dedicar mais atenção para as investigações que foquem em alguns sons específicos, produzidos por informantes gays e heterossexuais, no aspecto da produção e no da percepção. Esse parece ser um campo promissor, para os estudiosos da área, na constante busca por uma melhor compreensão acerca da relação entre a fala e a percepção da orientação sexual de pessoas. 
BARBUIO, E.; PAULINO, S. Gender perception by speech acoustic characteristics and pitch variability. Alfa, São Paulo, v.65, 2021.

- ABSTRACT: The research aimed atphoneticaly examining the speech of 14 men, 7 who declared themselves to be gay and 7 self-declared heterosexuals. The audio of these men's voices were submitted to tests of perception and judged by lay hearers judges. The theoretical assumptions of Variationist Sociolinguistics (LABOV, 2008 [1972]) and Eckert (1989, 1997, 2000, 2003, 2005, 2012; ECKERT; MCCONNELL-GINET, 2010), and Speech Perception, carried out by Gaudio (1994); Smyth, Jacobs and Rogers (2003); Levon (2007); CampbellKibler (2011); among others were used. Significant averages of pitch variability among gay informants were also verified. In most aspects, the averages of homosexual informants were closer to the averages of gay informants participating in English-language surveys than the averages presented by the heterosexual informants. Thus, due to the similarities of results with some surveys, it seems acceptable to affirm that there are some universal typical aspects that characterize a "gay speech".

- KEYWORDS: sociolinguistics; linguistic variation; linguistic perception; phonology; gay speech.

\section{REFERÊNCIAS}

BOERSMA, P.; WEENINK, D. Praat: doing phonetics by computer [Computer program]. Version 6.0.16. Disponível em: http://www.praat.org/. Acesso em: 16 ago. 2021.

BRAID, A. C. M. Fonética Forense: tratado de perícias criminalísticas. Campinas: Millenium, 2003.

CAMARGO, Z.; MADUREIRA, S. Voice quality analysis from a phonetic perspective: Voice Profile Analysis SchemeProfile for Brazilian Portuguese (BP-VPAS). In: CONFERENCE ON SPEECH PROSODY, 4., 2008, Campinas, Abstract Book and Proceedings [...], Campinas: Capes, Fapesp, CNPq, 2008. p.57-60. v.1.

CAMPBELL-KIBLER, $\mathrm{K}$. Intersecting variables and perceived sexual orientation in men. American Speech, New York, v.86, n.1, p.52-68, 2011.

CAMPBELL-KIBLER, K. The nature of sociolinguistic perception. Language Variation and Change, Cambridge, v.21, p.135-56, 2009.

CAMPBELL-KIBLER, K. Accent, (ing), and the social logic of listeners perceptions. American Speech, New York, v.82, n.1, p.32-64, 2007.

COLTON, R. H.; CASPER, J. C. Compreendendo os problemas da voz. Porto Alegre: Artes Médicas, 1996. 
COUPER-KUHLEN, E. An Introduction to English prosody. Baltimore: Edward Arnold, 1986.

CRUTTNDEN, A. Intonation. Cambridge: Cambridge University Press, 1986.

CRYSTAL, D. Dicionário de Linguística e Fonética. Rio de Janeiro: Jorge Zahar, 1988.

ECKERT, P. Three waves of variation study: the emergence of meaning in the study of sociolinguistic variation. Annual Review of Anthropology, Palo Alto, n.41, p.87-100, 2012.

ECKERT, P. Variation, convention and Social Meaning. In: ANNUAL MEETING OF THE LINGUISTIC SOCIETY OF AMERICA, Oakland, CA, Proceedings [...], Oakland, CA, 2005. Disponível em: http://www.justinecassell.com/discourse09/ readings/EckertLSA2005.pdf. Acesso em: 16 ago. 2021.

ECKERT, P. The meaning of Style. In: ANNUAL SYMPOSIUMABOUT LANGUAGE AND SOCIETY, 11., Austin, Proceedings [...], Austin: University of Texas, 2003. p.41-53.

ECKERT, P. Linguistic Variation as Social Practice. Hoboken: Blackwell Publishing, 2000 .

ECKERT, P. Age as a sociolinguistic variable. In: COULMAS, F. The handbook of Sociolinguistics. Oxford: Blackwell, 1997. p. 151-167.

ECKERT, P. The Whole Woman: Sex and gender differences in variation. Language Variation and Change, Cambridge, v.1, p.245-268, 1989.

ECKERT, P.; MCCONNELL-GINET, S. Comunidades de práticas: lugar onde co-habitam linguagem, gênero e poder. In: OSTERMANN, A. C.; FONTANA, B. Linguagem, gênero e sexualidade: clássicos traduzidos. São Paulo: Parábola, 2010. p.93-107.

EDWARDS, J. Refining our understanding of language attitudes. Journal of Language and Social Psychology, Clevedon, v.18, n.1, p.101-10, 1999.

FISKE, S. T.; NEUBERG, S. L. A continuum of impression formation, from categorybased to individuating processes: Influences of information and motivation on attention and interpretation. Advances in Experimental Social Psychology, San Diego, v.23, p.1-74, 1990.

FOULKES, P.; DOCHERTY, G. The social life of phonetics and phonology. Journal of Phonetics, London, v.34, n.4, p.409-438, October 2006.

GAUDIO, R. P. Sounding gay: Pitch properties in the speech of gay and straight men. American Speech, New York, v.69, n.1, p.30-57, 1994. 
GIBSON, E. J. How perception really develops: A view from outsidethe network, In: GIBSON, E. J. An Odyssey in Learning and Perception. Cambridge: MIT Press, 1991. p. 411-491. Original de 1977.

KENT, R. D.; READ, C. Análise Acústica da Fala. Tradução de Alexsandro Meireles. São Paulo: Cortez, 2015.

KENT, R. D.; READ, C. The Acoustic Analysis of Speech. San Diego: Singular Publishing Group, 1992.

KULICK, D. Gay and Lesbian Language. Annual Review of Anthropology, Palo Alto, v.29, p. 243-285, 2000.

LABOV, W. Padrões Sociolinguísticos. Trad.: Marcos Bagno; Marta Scherre e Caroline Cardoso. São Paulo: Parábola, 2008. Original de 1972.

LABOV, W. The Social Stratification of English in New York City. Washington, D.C.: Center for Applied Linguistics, 1966.

LABOV, W. The social motivation of a sound change, Word, New York, v.19, p.273-309, 1963.

LADEFOGED, P. Three areas of experimental phonetics. Londres: Oxford University Press, 1967.

LAKOFF G. Women, Fire and Dangerous Things. Chicago: London: University of Chicago Press, 1987.

LAVER, J.; WIRS, S.; MACKENZIE, J.; HILLER, S. M. A perceptual protocol for the analysis of vocal profiles. Edinburgh: Edinburg University, 1981. p.139-55. (Workin Progress, 14).

LEHISTE, I. Suprasegmentals. Cambridge: The MIT Press, 1970.

LEVON, E. Hearing gay: Prosody, interpretation and the affective judments of men's speech, American Speech, New York, v.81, n.1, p.56-78, 2007.

LINVILLE, S. E. Acoustic correlates of perceived versus actual sexual orientation in men's speech. Folia Phoniactrica et Logopaedica, Basel, v.50, n.1, p.35-48, 1998.

LOPES, L. W. Preferências e atitudes dos ouvintes em relação ao sotaque regional no telejornalismo. 2012. 141f. Tese (Doutorado em Linguística) - Universidade Federal da Paraíba, João Pessoa, 2012.

MCDONALD, E.; DEBOE, N.; WHITE, A. Acoustic and perceptual bases of judgments of women and men's sexual orientation from read speech. Journal of Phonetics, London, v.34, p.202-240, 2006. 
MOLLICA, M.C.; Fundamentação Teórica: conceituação e delimitação. In: MOLLICA, M.C.; BRAGA, M. L. (org.). Introdução à Sociolinguística: o tratamento de variação. São Paulo: Contexto, 2008. p.9-14.

MORAES, J. A. A entoação modal brasileira: fonética e fonologia. Caderno de Estudos Linguísticos, Campinas, v. 25, p. 101-111, 1993.

MUNSON, B. The acoustic correlates of perceived masculinity, perceived femininity, and perceived sexual orientations. Language and Speech, London, v.50, n.1, p.125-142, 2007.

MUNSON, B.; JEFFERSON, S.V.; MCDONALD, E.C. The influence of perceived sexual orientation on fricative perception. Journal of the Acoustic Society of America, Melville, n.119, p.2427-2437, 2006.

MUNSON, B.; MCDONALD, E. C.; DEBOE, N. L.; WHITE, A. R. The acoustic and perceptual bases of judgments of women and men's sexual orientation from read speech. Journal of Phonetics, London, v.34, n.2, p.202-240, 2006.

PIERREHUMBERT, J. The Phonology and Phonetics of English Intonation. Bloomington: Indiana University Linguistics Club Publications, 1987.

PODESVA, R. J. Phonation type as a stylistic variable: the use of falsetto in constructing a persona. Journal of Sociolinguistics, Hoboken, v.11, n.4, p.478-504, 2007.

ROGERS, H.; SMYTH, R. Phonetic diferences between gay- and straight - sounding male speakers of North American English. In: INTERNATIONAL CONGRESS OF PHONETIC SCIENCES, 15., Barcelona, Proceedings [...], Barcelona: Universitat Autonoma de Barcelona, 2003. p.1855-1858.

RYAN, E. E.; GILES, H.; SEBASTIAN, R. An integrative perspective for the study of attitudes toward language variation. In: RYAN, E.; GILES, H. (ed.). Attitudes Towards Language Variation: Social and Applied Contexts. London: Arnold, 1982. p. 1-19.

SMYTH, R.; JACOBS, G.; ROGERS, H. Male voices and perceived sexual orientation: an experiment and theoretical approach. Language in Society, Cambridge, v.32, p.329-350, 2003.

TARALLO, F. A pesquisa sociolinguística. São Paulo: Ática, 2007.

TRACY, E. C.; BAINTER SIERRA, A.; SANTARIANO, N. P. Judgments of selfidentified gay and heterossexual male speakers: Which phonemes are most saliente in determining sexual orientation? Journal of Phonetics, London, v.52, p.13-25, 2015.

ZWICKY, A. M. Two Lavander Issues for Linguistics. In: HALL, K.; LIVIA, A. (ed.). Queerly Phrased: Language Gender and Sexuality. Oxford: Oxford University Press, 1997. p.21-34. 
Recebido em 16 de março de 2020

Aprovado em 14 de agosto de 2020 